Der Sammelband untersucht das essayistische Schreiben im deutschsprachigen Raum zwischen 1900 und 1920 am Beispiel mehrerer Autoren und Themen. Die medialen Voraussetzungen, die die essayistische Diskursführung bestimmen, finden dabei besondere Beachtung. Aus den Positionen der behandelten Schriftsteller ergibt sich ein grundsätzlicher Konsens über die der Schriftsteller ergibt sich ein grundsatzlicher Konsens uber die der Jahrhunderts von gattungstypischen Konventionen imm Jahrhunderts von gattungstypischen Konventionen immer mehr abzukoppeln und ein selbststandiges hermeneutisches Profil anzunehmen, das dem Essay zu einer im Vergleich mit anderen literarischen Gattungen gesteigerten Diskursfahigkeit verhilft. Diese nimmt nach dem Zivilisationsbruch des Ersten Weltkrieges insofern völlig neue Konturen an, als sich der an der Tradition vormoderner sozialer Formen orientierende bildungsbürgerliche Horizont von nun an mit den Bedürfnissen einer viel komplexeren Gesellschaft konfrontiert sieht, was entweder zum radikalen Bruch mit alttradierten fiktionalen Strukturen realistischer Prägung führt oder zur Bewältigung solcher Komplexität aus drastisch apokalyptischer Sicht. Doch bis 1918 erscheint das essayistische Schreiben noch durch einen Hang zum Entwurf diskursiver Antworten auf die Krise der Moderne vereinheitlicht, bei denen sich die Gattung Essay als eine hoch differeiziert argumentierende Struktur zur Verarbeitung kulturkritischer I

Der Band resultiert aus der Zusammenarbeit von an italienischen Universitäten sowohl sprach- als auch literaturwissenschaftlich tätigen Germanisten und Philosophiehistorikern.

A m S t e R d m er B eIträge

Z UR NEUEREN GERMANISTIK

$74 \stackrel{\circ}{\circ}$ Raum (1900-1920)

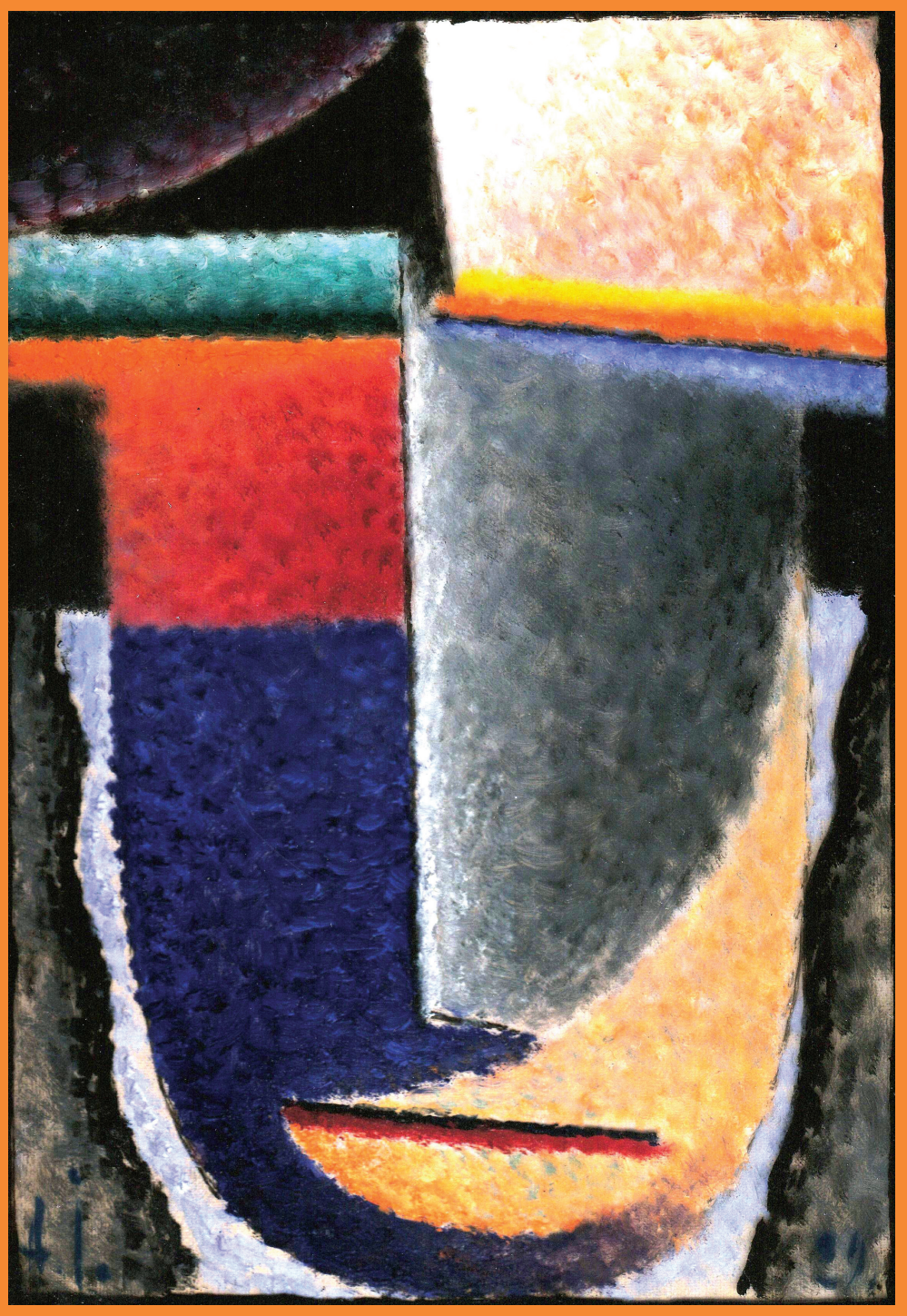

Herausgegeben von

Marina Marzia Brambilla und Maurizio Pirro 


\section{Wege des essayistischen \\ Schreibens im deutschsprachigen Raum (1900-1920)}




\section{A MSterdamer Beiträge ZUR NEUEREN GERMANISTIK

Herausgegeben von

Norbert Otto Eke

Martha B. Helfer

Gerhard P. Knapp

Gerd Labroisse 


\title{
Wege des essayistischen Schreibens im deutschsprachigen Raum (1900-1920)
}

\author{
Herausgegeben von \\ Marina Marzia Brambilla und Maurizio Pirro
}

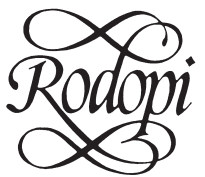

Amsterdam - New York, NY 2010 
Die 1972 gegründete Reihe erscheint seit 1977 in zwangloser Folge in der Form von Thema-Bänden mit jeweils verantwortlichem Herausgeber.

Reihen-Herausgeber:

Prof. Dr. Norbert Otto Eke

Universität Paderborn

Fakultät für Kulturwissenschaften, Warburger Str. 100, D - 33098 Paderborn,

Deutschland, E-Mail: norbert.eke@upb.de

Prof. Dr. Martha B. Helfer

Rutgers University

172 College Avenue, New Brunswick, NJ 08901

Tel.: (732) 932-7201, Fax: (732) 932-1111, E-mail: mhelfer@rci.rutgers.edu

Prof. Dr. Gerhard P. Knapp

University of Utah

Dept. of Languages \& Literature, 255 S. Central Campus Dr. Rm. 1400

Salt Lake City, UT 84112, USA

E-Mail: gerhard.knapp@m.cc.utah.edu

Prof. Dr. Gerd Labroisse

Sylter Str. 13A, 14199 Berlin, Deutschland

Tel./Fax: (49)30 89724235 E-Mail: Labroisse@t-online.de

Cover Image: Alexej von Jawlensky, Grosser Kopf, 1929 (Ö1, Karton)

All titles in the Amsterdamer Beiträge zur neueren Germanistik (from 1999 onwards) are available online: See www.rodopi.nl Electronic access is included in print subscriptions.

The paper on which this book is printed meets the requirements of "ISO 9706:1994, Information and documentation - Paper for documents Requirements for permanence".

ISBN: 978-90-420-2861-6

E-Book ISBN: 978-90-420-2862-3

CEditions Rodopi B.V., Amsterdam - New York, NY 2010

Printed in The Netherlands 


\section{Inhaltsverzeichnis}

Vorbemerkung

Andrea Pinotti: Dingsuche. Der Essayist Georg Simmel 11

Marina Marzia Brambilla: Die essayistischen Schriften Hermann Bahrs

Marco Castellari: Karl Wolfskehl als Essayist um die

Jahrhundertwende (1894-1914)

Maurizio Pirro: Die Natur als zivilisationskritische

Projektionsfläche im essayistischen Werk Carl Dallagos 71

Stefania Sbarra: Heinrich Manns Essays: polarisierende Prosa 93

Michele Sisto: Wider die 'literaturkritische Makulatur'.

Theodor Lessings schiefe Laufbahn vom Dichter zum Publizisten

Roberta Bergamaschi: Zwischen 'Syntaxauflösung' und 'mise en abîme'. Karl Kraus und das frühe 20. Jahrhundert

Marco Rispoli: Die Einheit in der Vielfalt. Bemerkungen zu Hofmannsthals essayistischer Prosa

Francesca Tucci: Der Künstler, der Literat und die Widersprüchlichkeit des Deutschtums. Thomas Manns Essayistik 1893-1919

Elena Polledri: Rainer Maria Rilke. Ein Essayist?

Moira Paleari: Herwarth Walden. Ein Essayist der Moderne

Fiorenza Ratti: Der Begriff der Gestalt in Friedrich Gundolfs wissenschaftlichen Darstellungen

Massimo Salgaro: Die Geburt des Musilschen Essayismus aus den Formen des Essays

Joachim Gerdes: 'Das Objekt dient immer dem Subjekt nur als Vorwand' - Stefan Zweigs Essays

Veronica Piccolo: Kurt Hiller zwischen Leben und Schreiben, Eros und Logos: Der schwierige Weg eines ethischen Geistes 
Markus Ophälders: Der Essay als Form im Schaffen des jungen Lukács

Loretta Monti: 'Das vergrabene Gesicht dieser Zeit'.

Hugo Balls Widerstand gegen die Geschichte

Luca Zenobi: 'Herr Doktor, ich höre, Sie besteigen auch den Pegasus?' Gottfried Benns frühe Essays

Maria Grazia Nicolosi: Zwischen 'angewandter Philosophie' und 'rationaler Lyrik'. Bemerkungen zur frühen Essayistik Hermann Brochs

Milena Massalongo: Kritisches Schreiben als 'historisches Experiment'. Walter Benjamins 'esoterischer Essay'

Autorenverzeichnis 


\section{Francesca Tucci}

\section{Der Künstler, der Literat und die Widersprüchlichkeit des Deutschtums. Thomas Manns Essayistik 1893-1919}

The increasing importance which Thomas Mann attributes in his fictional work to forms of assimilation which are critical of tradition, such as irony and parody, also produces significant consequences in his essay writing, and in the speculative process which underlies it. Mann aspires in particular to relativise the idea, typical of the political conservatism of the late nineteenth century, that German identity was to be defined as the sense of an uninterrupted continuity between past and present. He opposed this idea with a conservatism of an aesthetic type, which defined Germanness not in a uniquely affirmative sense, but on the basis of contradictory elements in a dialectic confrontation. At the centre of this process there is the figure of the artist, which Mann invests in his essay writing with the attributes which belong to his own narrative work: a double nature, contradiction, multiplicity. All Mann's essay writing can be seen as the mis-en-scène in heterogeneous historical, political and cultural contexts of the aspects of crisis which condition the activity of the artist.

Bei den verbindenden Elementen, die der Verwandtschaft zwischen den von Thomas Mann bis 1918 verfassten Aufsätzen und seinen 1919 veröffentlichten Betrachtungen eines Unpolitischen auch über die reine zeitliche Nähe hinaus eine unübersehbare geistige Prägung verleihen, handelt es sich nicht nur um Gemeinsamkeiten inhaltlicher oder ideologischer Art. Das einheitliche Profil der essayistischen Produktion, die Manns eigentliche fiktionale Arbeit schon seit Anfang seiner schriftstellerischen Tätigkeit auf durchaus paritärer Ebene begleitet, macht vielmehr die gedankliche Führung der intellektuellen Auseinandersetzung aus. Durch das gesamte Spektrum von Manns essayistischem Schreiben zieht sich ein homogenes argumentatives Verfahren, das mit seiner ausgeprägten Tendenz, eine relativ stabile Anzahl an Themen und Motiven in immer neu definierten Wechselbeziehungen so einzusetzen, dass aus einem solchen perspektivischen Zusammenspiel ein gesteigertes heuristisches Interesse entsteht, eine streng geregelte rhythmische Kombinatorik herstellt. Der musikalische Charakter der Betrachtungen wurde mehrfach betont durch ein musikalisches Konzept zeichnen sich Manns frühe Aufsätze ebenfalls aus. Genauso wie in den Betrachtungen kann man hier von "Variationen über ein Thema" sprechen, ein Thema, das in beiden Fällen das Schicksal erfährt, keine "präzisere Gestalt" ${ }^{1}$ zu gewinnen, und um Kunst, Künstler und Künstlertum kreist. Allen diesen Schriften ist unabhängig von ihrem Umfang ein

${ }^{1}$ Thomas Mann: Betrachtungen eines Unpolitischen. Frankfurt/M.: Fischer 2004. S. 32. 
kaum zu befriedigendes "Bedürfnis nach Gleichgewicht"2 gemeinsam. Die Annäherung an den behandelten Gegenstand erfolgt über wiederholte Perspektivenverschiebungen, die das Objekt aus immer neuen Blickwinkeln präsentieren und dem Autor selbst zu immer neuen Standortbestimmungen verhelfen. Die Inhalte werden jedes Mal kontrapunktisch variiert und über dem Ganzen herrscht "jen[e] dichterisch[e] Sophistik, welche den Recht haben lässt, der eben redet". ${ }^{3}$ Das Autobiographische und das Dichterische verflechten sich miteinander, Leben, Kunst und Werk erscheinen als untrennbar vermischt, und was dauernd thematisiert wird, ist das eigene "ganz[e] Selbst", denn die Rede ist immer "von mir", ${ }^{4}$ d. h. von der eigenen Person des Schriftstellers. ${ }^{5}$

Impuls nehmen Manns Essays aus den verschiedensten Anlässen. Mehreren ist ein Gelegenheitscharakter eigen, der durch den Eifer bedingt ist, mit dem Thomas Mann auf von Zeitschriften oder einzelnen Publizisten initiierte Umfragen eingeht. Die mehr oder weniger zufälligen Umstände, unter denen viele derartige Schriften entstehen, schließen allerdings eine durchdachte Ausarbeitung des jeweiligen Themas keinesfalls aus. Aufgefordert, zu in der Öffentlichkeit breit debattierten Fragen oft kulturkritischer Ausrichtung Stellung zu nehmen, stürzt sich Mann in deren spekulative Auffassung und schriftliche Gestaltung ohne Rücksicht auf bereits laufende fiktionale Unternehmen, die hierdurch eine Weile ruhen müssen. Diese Überkreuzung von essayistischem und erzählerischem Schreiben geschieht freilich nicht, ohne dass sich der Autor bedrängt, überfordert und in seinem schöpferischen Vermögen gar beeinträchtigt fühlt. Als er sich 1907 an einer Umfrage der Zeitschrift Nord und Süd beteiligt, die führende Persönlichkeiten aus der deutschsprachigen Kulturszene um ein Wort darüber gebeten hatte, welchen Einfluss das Theater auf ihre ästhetische Erziehung ausgeübt hatte, macht Mann in einem verschollenen, in einem seiner Notizbücher zum Teil erhaltenen Brief an Moritz Heimann, den damaligen Lektor bei Fischer-Verlag, aus der Aufdringlichkeit eines solchen Begehrens und dem Widerwillen, mit dem er sich zur Arbeit regelrecht gezwungen hat, keinen Hehl:

Vor mehreren Wochen kam mir eine Umfrage der Zeitschrift 'Nord u. Süd' zu: 'Was halten Sie vom Theater' etc. Ich erinnere mich nicht genau, wie die Fragen

${ }^{2}$ Ebd. S. 33.

${ }^{3}$ Ebd.

${ }^{4}$ Thomas Mann: Bilse und Ich. In: Große Kommentierte Frankfurter Ausgabe. Werke - Briefe - Tagebücher. Hg. von Heinrich Detering u. a. Band 14/1: Essays I. 1893 - 1914. Hg. von Heinrich Detering unter Mitarbeit von Stephan Stachorski. Frankfurt/M.: Fischer 2002. S. 110.

${ }^{5}$ Vgl. dazu Hermann Kurzke: Thomas Mann. Das Leben als Kunstwerk. München: Beck 1999. 


\begin{abstract}
formulirt waren. - Nur weiß ich, daß ich es mir eigentlich einfürallemal verbieten sollte, mich auf solche Dinge einzulassen, weiß aus mehrfacher Erfahrung, daß eine michselbst einigermaßen befriedigende Beantwortung solcher Fragen mich Zeit und Nervenkraft kostet, daß ich bei meiner Musik bleiben sollte und daß ich bei der Schriftstellerei das peinvolle Gefühl nicht los werde, mich unnütz zu compromittiren. Aber es hilft nichts: ich werde, wie es scheint das Schriftstellern nie ganz lassen können. Ich werfe mich von Zeit zu Zeit mit einer Leidenschaft darauf, die ich beim 'Musiziren' einfach nicht kenne. Dafür ist dann die Ernüchterung, der Katzenjammer, das Gefühl der Entkräftung, ja die Reue nachher desto größer. ${ }^{6}$
\end{abstract}

Wie dies ausgerechnet in dem aus jener Umfrage resultierenden Versuch über das Theater der Fall ist, erwächst aber aus der Unlust subtilste Klärungsarbeit, die bei Mann wiederum zur kunsttheoretischen Vorlage für den fiktionalen Teil seiner Tätigkeit dient. Weniger als eine Gefährdung stellt die Nüchternheit der essayistischen Reflexion für den Romanschriftsteller den Ausgangspunkt zur stofflichen Präzisierung von Themenkomplexen, Nuancierung von in erzählerischen Kontexten agierenden Figuren, sogar Umgestaltung wesentlicher struktureller Kompositionsprinzipien dar, wie die Dominanz der Austragung ideologischer Konflikte über die Darstellung erlebter Handlung im Zauberberg (1924) beweisen wird. ${ }^{7}$

Der ständige Übergang von einer Gattung zur anderen hat nicht zuletzt die Tatsache zur Folge, dass bestimmte Passagen als Gemeingut des Erzählers und des Publizisten aufgrund ihrer Aussagekraft über jedwede gattungsbedingte Grenze hinaus in völlig verschiedenen Konstellationen eingesetzt werden. Gustav von Aschenbach wird bekanntlich in Der Tod in Venedig (1913) als Urheber von Werken zum Teil essayistischer Prägung präsentiert, die Mann selbst entweder bereits unausgeführt hatte liegen lassen oder später in stark veränderter Form niederschreiben sollte. In mehreren Essays aus den Jahren von 1905 bis 1910 kommt außerdem ein Hinweis auf ein Wort Schillers ("so wirst du mir gerne glauben, daß es mir immer eine schwerere Arbeit ist, einen Brief des Julius zu schreiben, als die beste Szene zu machen") vor, das Mann seinen fiktiven Schiller in Schwere Stunde (1905) so gut wie wortwörtlich sprechen lässt und das aus dem Brief Schillers an Christian Gottfried Körner vom 14. November 1788 stammt. Dort konnte Mann den Widerspruch von "Musik" und "Schriftstellerei" schon vorgezeichnet finden, den er dann in seiner Mitteilung an Heimann zum Ausdruck bringen sollte. Die Austauschbarkeit

\footnotetext{
${ }^{6}$ Thomas Mann: Notizbücher 7-14. Hg. von Hans Wysling und Yvonne Schmidlin. Frankfurt/M.: Fischer 1992. S. 169.

${ }^{7}$ Wichtiges dazu bei Elisabeth Galvan: Identifikation und Identität. Thomas Mann und Friedrich der Große. In: Linke und rechte Kulturkritik. Interdiskursivität als Krisenbewußtsein. Hg. von Gilbert Merlio und Gérard Raulet. Frankfurt/M.: Lang 2005. S. 287-302.
} 
von Zitaten und Quellenbezügen ist ein klares Zeichen dafür, dass in der Praxis der literarischen Erfindung Essay und Fiktion viel günstiger aufeinander einwirken, als die erbitterte Briefäußerung Manns vermuten ließe.

Basiert die für die essayistische Produktion Manns typische Dynamik auf der ständigen Oszillation zwischen Gegenpolen, die weniger nach ihrem selbstständigen Wert als vielmehr im Lichte ihrer gegenseitigen Beziehungen überprüft werden, so können sämtliche diesem Schriftsteller vertrauten Polaritäten unter dem fundamentalen Gegensatz von 'Plastischem' und 'Kritischem' subsumiert werden. Manns perspektivisches Verfahren kommt insbesondere dort zur Geltung, wo es darum geht, unterschiedliche Typologien von künstlerischer Existenz nicht als Ausdruck vorgegebener Wertsetzungen auszulegen, sondern als pragmatisch bedingte Formen der Selbstorientierung im Hinblick auf ihre Brauchbarkeit für die kreativen Aufgaben des Künstlers zu begutachten. Artistik und soziales Engagement, ethische Unverantwortlichkeit des seinem Willen zum Schaffen anheim gegebenen Schöpfers und strenge Sittlichkeit des urteilenden Intellektuellen wertet Mann als gleichberechtigte Extreme auf, die das dialektische Geschick des sie souverän handhabenden Künstlers in ihrer latenten Verwandtschaft entlarvt. Insofern sieht Mann nicht nur keinen prinzipiellen Gegensatz zwischen dem Drang nach synthetischer Harmonisierung des Disparaten, dem seine fiktionalen Werke unterliegen, und der Neigung zur analytischen Sonderung, die den Bemühungen des Essayisten innewohnt. Im Gegenteil steigert der Künstler gerade durch die dialektische Wechselwirkung zwischen dem einen und dem anderen seine Fähigkeit, das Stoffliche ästhetisch zu bewältigen. Aus dieser dialektischen Überwindung von Gegensätzen, in der der charakteristische Habitus des Essayisten Thomas Mann zu sehen ist, ${ }^{8}$ geht jene Verschmelzung hervor, die Mann nicht selten als "das dritte Reich" vorschwebt, wie es am Schluss des Ende 1912 anlässlich der Uraufführung des gleichnamigen Stückes verfassten Kurzaufsatzes Zu "Fiorenza" lautet:

Es hat niemals einen durchaus 'naiven', niemals einen durchaus 'sentimentalischen' Dichter gegeben - die Worte in ihrer reichsten und tiefsten Bedeutung genommen. Denn der Dichter ist die Synthese selbst. Er stellt sie dar, immer und überall, die Versöhnung von Geist und Kunst, von Erkenntnis und Schöpfertum, Intellektualismus und Einfalt, Vernunft und Dämonie, Askese und Schönheit - das dritte Reich. ${ }^{9}$

Ein solches verbindendes Drittes wird aber selbst insofern Gegenstand der dialektischen Überprüfung, als Mann keinen Zweifel daran hegt, dass den

\footnotetext{
${ }^{8}$ Vgl. dazu Herbert Lehnert: Thomas Manns Modernität. In: Thomas Mann Jahrbuch 18 (2005). S. 265-275.

${ }^{9}$ Thomas Mann: Zu "Fiorenza". In: Große Kommentierte Frankfurter Ausgabe (wie Anm. 4). Band 14/1. S. 348f.
} 
Polaritäten, die es in Einklang bringen sollte, jede erdenkliche Substantialität abhanden gekommen ist, und ihnen nichts als symbolische Bedeutung zu bescheinigen ist. Dem modernen Künstler kommt es nicht darauf an, die eine oder die andere Typologie in einer Art unverbrauchter Authentizität anzustreben, sondern Kategorien wie 'naiv' und 'sentimentalisch' in ihrem nunmehr sekundären und rein paradigmatischen Wert zu erkennen. "Das dritte Reich" erweist sich insoweit als literarisches Gebilde, das seine Wirkung eher im Rahmen der poetischen Erfindung entfaltet. Über die Tatsache, dass sich die künstlerische Arbeit nicht auf der primären Ebene einer ursprünglichen Einheit mit der Welt abspielen darf, sondern nur durch die Auseinandersetzung mit der Tradition möglich gemacht wird, ist sich Mann durchaus im Klaren. ${ }^{10}$ In der dritten Notiz aus dem Konvolut von Aufzeichnungen, die zu einem zusammenhängenden Essay mit dem Titel Geist und Kunst hätten führen sollen, liest man dazu eine deutliche Stellungnahme:

Was heißt überhaupt 'literarisch' im verächtlichen Sinne? Alles, was nicht unmittelbar auf Lebensanschauung beruht, sondern auf Bücher, Lektüre zurückzuführen ist? Aber darf man Bücher u. Lektüre unterschätzen? Kann man schreiben, ohne gelesen zu haben? Steht nicht einer auf den Schultern des Anderen? [...] Das ursprüngliche Genie ohne Lektüre ein Aberglaube. Was ist poetische Cultur, wenn nicht das Lernen; Übernehmen, selbst nachahmen? [...] Tradition. Geschichte. Schulung des Blicks durch Bücher. Es ist doch in allen Künsten so. ${ }^{11}$

1909, nachdem er den Roman Königliche Hoheit abgeschlossen hat, plant Mann einen äußerst anspruchsvollen Essay, der in der ihm zugrunde liegenden Absicht, weit gespannte Fragen kunsttheoretischer und -kritischer Art aufzugreifen, ganz offensichtlich mit Schillers Essay Über naive und sentimentalische Dichtung zu konkurrieren gedenkt, wie die Tatsache bestätigt, dass in Der Tod in Venedig eine direkte Verbindung zwischen der lediglich in der Fiktion vervollständigten, Gustav von Aschenbach zugeschriebenen Abhandlung Geist und Kunst und Schillers Schrift hergestellt wird, durch eine gewisse Ähnlichkeit von "ordnende[r] Kraft und antithetische[r] Beredsamkeit". ${ }^{12}$ Weiter als zu einer unordentlichen Ansammlung von verstreuten Notizen kommt es aber nicht, wahrscheinlich gerade wegen mangelnder "ordnende[r]

\footnotetext{
${ }^{10} \mathrm{Zu}$ diesen Themen vgl. die einleuchtenden Bemerkungen von Paolo Chiarini: Brecht, Lukács e il realismo. Roma-Bari 1983. S. 14ff.

${ }^{11}$ Manns Notate wurden 1967 von Hans Wysling im ersten Band der Reihe 'ThomasMann-Studien' mit umfangreichem Kommentar ediert. Hans Wysling: "Geist und Kunst". Thomas Manns Notizen zu einem "Literatur-Essay". In: Paul Scherrer Hans Wysling: Quellenkritische Studien zum Werk Thomas Manns. Bern-München: Francke 1967. S. 123-233. Hier: S. 153 (Notiz 3).

${ }^{12}$ Thomas Mann: Der Tod in Venedig. Frankfurt/M.: Fischer 1992. S. 19.
} 
Kraft". Manns Themenstellung sträubt sich gegen jeden Versuch, mit ihr systematisch fertigzuwerden. Die Brisanz der hier behandelten Probleme rückt aber den ungeschriebenen Aufsatz in eine Schlüsselstellung innerhalb Manns Essayistik dieser Zeit. Auf die hier niedergeschriebenen Gedanken greift Mann wiederholt in etlichen Schriften der Vorkriegsjahre, in seiner Kriegspublizistik (allen voran in den 1914 veröffentlichten Gedanken im Kriege, die sich bei der berühmten Unterscheidung von 'Kultur' und 'Zivilisation' auf Vorbereitungsmaterialien zum 'Literatur-Essay' stützen) und nicht zuletzt an mehreren Stellen der Betrachtungen eines Unpolitischen zurück. Auf die Wichtigkeit der theoretischen Arbeit, die Mann bei diesem gescheiterten Unternehmen leistet, hat mit großem Nachdruck Hermann Kurzke hingewiesen, der den unausgeführten Essay aufgrund seiner Ausstrahlung in die verschiedensten Richtungen des Oeuvres Thomas Manns als "geheimes Zentrum [seiner] frühen Ästhetik" ${ }^{13}$ bezeichnet.

In den Notizen zu Geist und Kunst beschäftigt sich Mann mit dem Problem einer klaren Definition des Künstlers, des Dichters und des Literaten in ihrem jeweiligen Wesen und in ihren gegenseitigen Beziehungen. Obwohl diese Kategorien einer ständigen kritischen Überprüfung unterzogen werden, bemüht sich Mann um keine eindeutige Stellungnahme zu ihrem jeweiligen Wert. Die früheren Aufzeichnungen stehen im Schatten einer leidenschaftlichen Aufwertung des Literaten und seines Erkenntnispotenzials. Ihm, der im Fahrwasser Nietzsches ein für alle Mal als gleichberechtigt mit dem Dichter betrachtet wird, ist nichts Künstlerisches fremd, sein Hang zur differenzierten Darstellung des Realen erlangt durchaus ästhetischen Wert. Für Mann steht außer Frage, dass "solche Welt- und Herzenskenner und -Künder wie die großen Schriftsteller, die nicht unmittelbar u. sinnlich darstellten, sondern redeten und aussprachen und bezeichneten" ${ }^{14}$ auch Künstler heißen sollten. Die langsame, in Details verweilende Erfassung der Wirklichkeit, der der Kritiker nachgeht, strahlt genauso wie der auf unmittelbarer Ergießung der Seele basierte Gesang des Dichters poetische Brillanz aus. Hier scheint Mann keinen Gegensatz zwischen der aus der Romantik stammenden Vorstellung des dichterischen Berufes und dem für die Jahrhundertwende charakteristischen Typus des Literaten als zergliedernden Kulturkritikers wahrzunehmen. In Anlehnung an eine Formulierung Stefan Georges schreibt er:

Darstellung, Plastik, Mittelbarkeit, persönliches Verschwinden sind [...] so wenig das Criterium des Dichter- und Künstlertums, daß vielmehr der Lyriker (doch wohl der Dichter par excellence!) kein Indirekter, kein Plastiker und Symboliker, sondern ein

${ }^{13}$ Hermann Kurzke: Thomas Mann. Epoche - Werk - Wirkung. München: Beck $1997^{3}$. S. 87.

${ }^{14}$ In: Wysling (wie Anm. 11). S. 167 (Notiz 27). 
unmittelbarer Sprecher und Bekenner ist. Aber lehrte nicht von Urzeiten das apollinische Doppel-Symbol der Leier und des Bogens - hat nicht zuletzt noch der großartige, wundervolle Fall Nietzsche die Zusammengehörigkeit, die Verwandtschaft, die Identität von Lyrik und Kritik gelehrt? Wir sehen, alltäglich, den Kritiker nur in seinen niedrigsten Typen, als Schulmeister, als Nörgler, als Parodisten, als wachsamen, maulscharfen und im Grunde feindseligen Kunstaufseher. Aber der Kritiker hoher Art ist Lyriker und Bekenner. Selbstkritik. Polemik und Liebe. - - Wie ist es in Deutschland nach Nietzsche noch möglich, im 'Schriftsteller', im Kritiker etwas Inferiores und Gegensätzliches zum Dichter und Künstler zu sehen? ${ }^{15}$

Dichter und Literat handeln zwar unterschiedlich, in beiden Fällen ist aber "die selbe künstlerische Transformationskraft am Werke". ${ }^{16}$

Zum Befremden des sich mühsam in der Menge der nur angedeuteten Argumentationen orientierenden Lesers wird aber kurz darauf dem Künstlertypus, der nach Manns Wortgebrauch mit dem Dichter gleichbedeutend anzusehen ist, jede Verwandtschaft mit der gesunden Einstellung des Literaten abgesprochen. Er gilt nun als "unbändig interessante [...] Kreuzung von Lucifer und Clown"; ${ }^{17}$ parallel dazu verschiebt sich allerdings auch das Bild des Literaten, der im Lichte einer ambivalenten Eigenart präsentiert wird, die Mann mit einem Wort Nietzsches als "Zwischen-Spezies" 18 bezeichnet. Die Kluft zwischen den beiden Begriffen vergrößert sich weiter, indem Mann in Notiz 111 anmerkt, dass selbst der "raffinierteste" und auf alle möglichen Effekte bedachte Künstler "immer viel naiver und unwissender über sichselbst, unverantwortlicher, unschuldiger [ist], als der Litterat für möglich hält". ${ }^{19}$ Der Erkenntnistrieb des Kritikers ist an sich, "objektiv genommen", ${ }^{20}$ richtig, aber dieser kommt zu einer verfehlten Schlussfolgerung, wenn er versucht, aus seinen abstrakt fundierten Erkenntnissen ein Urteil über das Wesen des Künstlers zu fällen. Daraus folgt, wie in der nächsten Notiz behauptet wird, dass es "zweifellos gesünder" wäre, "Kunst, als Analyse zu treiben", ${ }^{21}$ was mit allen vorherigen Aussagen reinen Tisch macht und die Position Manns in die Nähe der kurz zuvor streng getadelten Trennung von Leier und

\footnotetext{
${ }^{15}$ Ebd. S. 170f. (Notiz 40).

${ }^{16}$ Ebd. S. 174 (Notiz 46).

${ }^{17}$ Ebd. S. 182 (Notiz 59).

${ }^{18}$ Ebd. S. 184 (Notiz 62). Mann zitiert aus dem Aphorismus 389 vom 1901 als Band 15 der 'Großoktavausgabe' Nietzsches aus dem Nachlass des Philosophen edierten Willen zur Macht. Nietzsches Notiz liest man in Nietzsche: Werke. Kritische Gesamtausgabe. Begründet von Giorgio Colli und Mazzino Montinari. Weitergeführt von Wolfgang Müller-Lauter u. Karl Pestalozzi. Band 8/3. Berlin-New York: de Gruyter 1972. S. 158f.

${ }^{19}$ In: Wysling (wie Anm. 11). S. 211 (Notiz 111).

${ }^{20} \mathrm{Ebd}$.

${ }^{21}$ Ebd. S. 212 (Notiz 112).
} 
Bogen rückt. Desto befremdender wirkt dann die unmittelbar danach folgende Aussage, die Künstler und Literat wieder zusammenbringt und sogar als zwei Seiten ein und derselben Seele darstellt, die auch die des Thomas Mann selbst ist. Er kann nichts dafür, so heißt es in Notiz 112, wenn der in ihm versteckte Literat "unweigerlich nach Bethätigung verlangt". ${ }^{22}$

Vergeblich würde man versuchen, anhand der verschiedenen Charakterisierungen eine feste Grenze zwischen diesen zwei Figuren zu ziehen, die Mann immer wieder skizziert; die eine ist überhaupt nicht ohne die andere denkbar. Aus dieser Perspektive kommt schon hier eindeutig zutage, was für ein zerreiBender innerer Konflikt derjenige sein wird, der durch die Betrachtungen eines Unpolitischen zwischen Dichter und Zivilisationsliterat heraufbeschworen und ausgetragen wird. In Anbetracht dessen, dass den beiden Typologien - ihrer dauernden kritischen Relativierung zum Trotz - ein erhebliches künstlerisches Potenzial zuerkannt wird, lohnt sich der Versuch ohnehin, auf mögliche Übereinstimmungen hinzuweisen. Dabei geht es nicht so sehr um die Suche nach einer zwar wünschenswerten, doch schwer zu verwirklichenden Synthese, sondern eher darum, mit den gemeinsamen Merkmalen der Kategorien 'Dichter' und 'Literat' ins Klare zu kommen, um die dialektische Polarität dieser untrennbaren und äußerst fruchtbaren Wechselbeziehung in den Vordergrund treten zu lassen.

Gerade aufgrund ihrer künstlerischen Veranlagung sind sowohl der Dichter als auch der Literat aus gesellschaftlicher Perspektive tendenziell unzuverlässige Individuen. In der kurzen Schrift Im Spiegel, die Mann zwischen November und Dezember 1907 für eine Rubrik der Zeitschrift Das literarische Echo verfasst, lässt sich der Schriftsteller lang und breit über die soziale Unbrauchbarkeit des Dichters aus:

Ich weiß, was ein Dichter ist, denn bestätigtermaßen bin ich selber einer. Ein Dichter ist, kurz gesagt, ein auf allen Gebieten ernsthafter Tätigkeit unbedingt unbrauchbarer, einzig auf Allotria bedachter, dem Staate nicht nur nicht nützlicher, sondern sogar aufsässig gesinnter Kumpan, der nicht einmal sonderliche Verstandesgaben zu besitzen braucht, sondern so langsamen und unscharfen Geistes sein mag, wie ich es immer gewesen bin, - übrigens ein innerlich kindischer, zur Ausschweifung geneigter und in jedem Betrachte anrüchiger Charlatan, der von der Gesellschaft nichts anderes sollte zu gewärtigen haben - und im Grunde auch nichts anderes gewärtigt - als stille Verachtung. ${ }^{23}$

Was hier vom Dichter behauptet wird, kann genauso gut für den Literaten gelten, da beide im Grunde vom Vorwurf der Scharlatanerie getroffen sind.

\footnotetext{
${ }^{22}$ Ebd.

${ }^{23}$ Thomas Mann: Im Spiegel. In: Große Kommentierte Frankfurter Ausgabe (wie Anm. 4). Band 14/1. S. 184.
} 
Diese ist allerdings laut Nietzsche ein charakteristisches Element des modernen Künstlers, dessen ästhetisches Schaffen vor allem auf Mache beruht und auf Effekt zielt. Wenn Mann immer wieder darauf besteht, dass man Talent haben muss, wenn man künstlerisch auf hohem Niveau wirken will, ist es ihm nicht weniger klar, dass die Scharlatanerie selbst eine Art Talent ist, und dazu sehr zeitgemäß. ${ }^{24}$ In An einen jungen Dichter, einem kleinen, Anfang 1908 geschriebenen und unveröffentlicht gebliebenen Aufsatz, merkt Mann zum Thema Talent an, dass es sich dabei "viel weniger darum [handelt], ob Einer etwas kann, als darum, ob Einer etwas ist". ${ }^{25} \mathrm{Ob}$ jemand zum Künstler wird, ist zunächst einmal nicht eine Frage des Könnens, sondern des Seins, da der künstlerisch Begabte meist durch grundsätzliche Untauglichkeit gekennzeichnet ist:

Wenn Sie nichts in der Welt zu wollen und zu können glauben, als Schreiben, wenn Sie sich innerlich so zur Welt und zu den Menschen gestellt fühlen, daß die einzig mögliche Art von Bethätigung Ihnen das Träumen, Empfinden, Deuten, Gestalten, die einzig mögliche Wirkungsart die durch das Wort ist, - dann werden Sie Schriftsteller. Sonst nicht, sonst lieber nicht. ${ }^{26}$

Bei den beiden Schriftstellertypologien kommt es hauptsächlich auf die Fähigkeit an, sowohl sich selbst als auch sein literarisches Schaffen einer stilistischen Bewältigung zu unterziehen, die Brüche und Spannungen nicht etwa aufhebt, sondern dem sich gegen alle Widerspenstigkeit des Stofflichen durchsetzenden Willen zur Form unterordnet. Im Mittelpunkt des künstlerischen Schaffens steht die Größe, die einzig für ästhetische Ergebnisse hohen Stils sorgen kann, unabhängig davon, ob ein Schriftsteller sich auf 'plastischem' oder 'kritischem' Feld betätigt. Nur im Zeichen der Größe wird Kunst den das Frühwerk Thomas Manns auf entscheidende Weise prägenden Anforderungen des Lebens gerecht.

Der Bezug auf Größe als Grundlage zur Legitimation künstlerischen Tuns ist in Manns Essayistik des Öfteren zu finden. Als sich der Achtzehnjährige zu Heinrich Heine bekennt und diesen vor einem Rettungsversuch des Publizisten Konrad Scipio in Schutz nehmen will, der ihm in einem fragwürdigen Lichte als eher spießbürgerlich gesinnt erscheint, gipfeln seine höhnischen Aufzeichnungen in der Feststellung, dass "Heinrich Heine kein 'guter' Mensch [war]. Er war nur ein großer Mensch. - Nur...!" 27 In der 1915 erschienenen

\footnotetext{
${ }^{24}$ Vgl. dazu Eckhard Heftrich: Nietzsches tragische Größe. Frankfurt/M.: Klostermann 2000 (im besonderen das Kapitel Thomas Mann zwischen Wagner und Nietzsche. S. 183-217).

${ }^{25}$ Thomas Mann: An einen jungen Dichter. In: Große Kommentierte Frankfurter Ausgabe (wie Anm. 4). Band 14/1. S. 194.

${ }^{26}$ Ebd. S. 195.

${ }^{27}$ Thomas Mann: Heinrich Heine, der 'Gute'. In: Große Kommentierte Frankfurter Ausgabe (wie Anm. 4). Band 14/1. S. 23. Vgl. dazu Herbert Lehnert: Thomas
} 
Abhandlung über Friedrich und die große Koalition, die Manns Publizistik vor den Betrachtungen eines Unpolitischen gleichsam abschließt, fungiert Größe ganz offensichtlich als Bindeglied zwischen Kunst und Leben, indem die durch sie angeregten hohen Leistungen das Gemeine vom geistig Durchdrungenen trennen. Ästhetische Berufung und pragmatisches Handeln finden zu ihrem gemeinsamen Ursprung in einem Prinzip, das Dämonisches und Schicksalhaftes in sich trägt, bei dem aber jede glückliche Veranlagung dadurch eine feste Bestimmung zu erringen hat, dass sie sich konkreten, disziplinierenden Aufgaben stellt. In diesem Sinne lässt sich der preußische König von seiner Anziehung durch Philosophie und Literatur aus einem "geheimen Instinkt" wie aus Pflichtbewusstsein ablenken, um sich auf die "furchtbaren Anstrengungen und blutigen Schrecken des Krieges" 28 einzulassen.

Das eigentlich Heroische an der Größe besteht für Mann nicht etwa im Glanz ihrer Hervorbringungen, sondern in der Selbstüberwindung, zu der sich jedes Talent verpflichten muss, um sich durchzusetzen und sich in einer fest umrissenen Form verwirklichen zu können. ${ }^{29}$ Größe verkündet sich meist so Mann - als Herausforderung an widrige Umstände, als "ein Trotzdem [...], das trotz Kummer und Qual, Armut, Verlassenheit, Körperschwäche, Laster, Leidenschaft und tausend Hemmnissen zustande gekommen ist". ${ }^{30}$ Die Behauptung wäre jedenfalls falsch, Mann gebe sich mit einem solchen Bild der Größe als Ergebnis ermattender Bemühungen restlos zufrieden. Die klare Einsicht in den engen Spielraum, der dem modernen Künstler zur Entfaltung seines kreativen Potenzials zur Verfügung steht, schließt den nostalgischen Bezug auf einen unbeschwerten, 'naiven' Zustand angeborener Schöpfungskraft kaum aus. ${ }^{31}$ Mann sieht freilich ein, dass die sorglose Unverbindlichkeit des Künstlers als inspirierten Gotteslieblings, dessen Bild er aus seiner Romantik-Interpretation herleitet und in seinem Werk mehrfach umstrukturiert

\footnotetext{
Manns Politikverständnis, 1893-1914. In: Theodor Fontane und Thomas Mann. Die Vorträge des Internationalen Kolloquiums in Lübeck 1997. Hg. von Eckhard Heftrich u. a. Frankfurt/M.: Klostermann 1998. S. 77-97 (im Besonderen S. 81ff.).

${ }^{28}$ Thomas Mann: Friedrich und die große Koalition. In: Große Kommentierte Frankfurter Ausgabe (wie Anm. 4). Band 15/1: Essays II. 1914 - 1926. Hg. von Hermann Kurzke unter Mitarbeit von Joëlle Stoupy, Jörn Bender und Stephan Stachorski. Frankfurt /M.: Fischer 2002. S. 121.

${ }^{29}$ Vgl. dazu Gerhard Kluge: Friedrich, der König von Preußen, in Essays von Thomas und Heinrich Mann und der Bruderkonflikt. In: Thomas Mann Jahrbuch 12 (1999). S. 259-291.

${ }^{30}$ Thomas Mann: Dichterische Arbeit und Alkohol. In: Große Kommentierte Frankfurter Ausgabe (wie Anm. 4). Band 14/1. S. 115.

${ }^{31} \mathrm{Zu}$ dieser Konstellation gilt Hermann Kurzkes Dissertation als Standardtext: Auf der Suche nach der verlorenen Irrationalität. Thomas Mann und der Konservatismus. Würzburg: Königshausen und Neumann 1980.
} 
(z. B. in der Joseph-Tetralogie oder in seiner Aneignung der Gestalt Goethes), für den modernen Künstler nunmehr ausgedient hat. Die ergreifende Inspiration als Geschenk der Götter weicht der peinigenden Anstrengung, die zugleich jene "Moral des Künstlers" ausmacht, die Mann in seiner 1909 in der Wiener Neuen Freien Presse veröffentlichten Skizze Süßer Schlaf! als "Hingebung, Irrtum und Selbstverlust, [...] Kampf und Not, Erlebnis, Erkenntnis und Leidenschaft" 32 bezeichnet. Insofern wirkt eine "starke Begabung" als "ein Stachel zur Würde, zu hoher Geistigkeit der Aufgaben und Leistungen", ${ }^{33}$ wie es in den Vorarbeiten zu Geist und Kunst heißt. Das Vorhaben, mit dieser geplanten Abhandlung nicht zuletzt eine Bestandsaufnahme des gegenwärtigen Zustandes der deutschen Literatur zusammenzustellen, führt Mann dazu, seine Anschauungen zum Wesen der modernen Kunst am Beispiel mehrerer spezifischer Fälle darzulegen. Bei den Inszenierungen Max Reinhardts sieht er eben die steigernde Kraft eines unermüdlichen Fleißes am Werk, der als Ersatz für fehlende ursprüngliche Genialität eingesetzt werden kann:

Der Fall Reinhardt: für mich ein künstlerisches Erlebnis hohen Ranges. Es ist nämlich ein ermutigendes, michselbst bestätigendes Erlebnis. Daß Modernität, daß Kleinheit, Détail-Addition, Geniemangel, Intellektualität, verbunden mit Zähigkeit, Arbeit, Willensdauer, sich mit Glück an Aufgaben großen Styles wagen darf: der Fall Reinhardt beweist es. ${ }^{34}$

In Anlehnung an Nietzsches Wagner-Kritik ist sich Mann darüber völlig im Klaren, dass die Aneinanderreihung von gesonderten Details den für die Kunst um die Jahrhundertwende typischen Verlust an Totalität nicht wiedergutmachen kann. Insoweit kommt der ästhetischen Arbeit in der Moderne ein sekundärer Charakter zu, der in der Kombinatorik zum Vorschein kommt, die dem Schöpfungsprozess zugrunde liegt. Seine Arbeit führt der moderne Künstler nicht durch selbstständige Erfindung aus, sondern vielmehr dadurch, dass er sich mit tradierten Bildungsgütern intensiv auseinandersetzt, um daraus ein neues Werk zu gewinnen, bei dem das Handwerkliche als souveräner Umgang mit Quellen und Zitaten den wesentlichen Anteil am Aufbau des Kunstwerkes hat. Der Originalitätsanspruch, den der Künstler noch erheben kann, verschiebt sich vom rein Stofflichen zu der Fähigkeit, vorgegebene Materialien durch Umgestaltung wiederzubeleben. Dieses Verfahren hat Mann in Bilse und ich, einem seiner bekanntesten Essays, ausführlich beschrieben. Als 1905 in einem Gerichtsverfahren wegen Beleidigung, das gegen einen Schriftsteller in die Wege geleitet worden war, Manns Buddenbrooks mit einem trivialen

\footnotetext{
${ }^{32}$ Thomas Mann: Süßer Schlaf! In: Große Kommentierte Frankfurter Ausgabe (wie Anm. 4). Band 14/1. S. 207.

${ }^{33}$ In: Wysling (wie Anm. 11). S. 182 (Notiz 59).

${ }^{34}$ Ebd. S. 206 (Notiz 102).
} 
Schlüsselroman verglichen wird, springt dieser in die Bresche, um seinen Roman vor dem Vorwurf zu verteidigen, er habe nichts als existierende Personen und Umstände sklavisch kolportiert. Nicht auf Erfindung inhaltlicher Zusammenhänge kommt es bei der künstlerischen Leistung an, sondern auf jene Transfiguration des Tatsächlichen, die Mann als "Beseelung" bezeichnet:

Die Beseelung... da ist es, das schöne Wort! Es ist nicht die Gabe der Erfindung die der Beseelung ist es, welche den Dichter macht. Und ob er nun eine überkommene Mär oder ein Stück lebendiger Wirklichkeit mit seinem Odem und Wesen erfüllt, die Beseelung, die Durchdringung und Erfüllung des Stoffes mit dem, was des Dichters ist, macht den Stoff zu seinem Eigentum, auf das, seiner innersten Meinung nach, niemand die Hand legen darf. ${ }^{35}$

Spitzen sich diese Anschauungen vier Jahre später in der Formulierung, "das Parodische" sei bei jedem Künstler "die Wurzel" ${ }^{36}$ noch zu, so wohnt Manns Gedankenführung eine unübersehbare Tendenz inne, die säkularisierte Vorstellung des Künstlers als auf Skepsis und Spekulation pochenden Kulturkritikers in einen durch romantische Kategorien und Wortprägungen gekennzeichneten Horizont einzubinden. So sehr Mann Erkenntnis und Genauigkeit der analytischen Beobachtung als spezifische Dimension der künstlerischen Tätigkeit um die Jahrhundertwende aufwertet, kann er doch den Verdacht nicht von sich weisen, in einem solchen bewussten Verzicht auf Ganzheit komme weniger eine gesteigerte, der erhöhten Sensibilität der Moderne angemessene Ausdrucksform zum Vorschein, als vielmehr eine Verarmung an schöpferischem Vermögen und dichterischer Unmittelbarkeit. Genauso deutlich sieht er dabei aber ein, dass die sehnsüchtige Hinwendung zu einem verlorenen Ideal ungebrochener Totalität nicht nur zivilisationskritische Ansätze allgemeiner, zeitverbundener Art mit sich bringt, sondern seine eigene Identität als bekennendes Mitglied jener "Schule von Geistern [...], in welcher man sich gewöhnt hat, den Begriff des Künstlers mit dem des Erkennenden zusammenfließen zu lassen", ${ }^{37}$ hinterfragt und in einen äußerst kritischen Zustand stürzt. Über die Tatsache, dass "manches" an seiner essayistischen Arbeit "im Grunde Selbstkritik" ist und "viele der kritisierten Tendenzen" 38 auch in ihm vorhanden sind, weiß er immerhin nur zu gut Bescheid, woraus sich die gereizte und von Ressentiment überladene Prosa der Betrachtungen eines Unpolitischen speisen wird.

Dass der Zwiespalt zwischen Plastischem und Kritischem Manns eigene ästhetische Anschauung bis ins Tiefste durchdringt, beweist nicht zuletzt das ständige, nicht selten ins Extrem des virtuosen Jonglierens ausartende Pendeln

${ }^{35}$ Mann: Bilse und ich (wie Anm. 4). S. 100.

${ }^{36}$ In: Wysling (wie Anm. 11). S. 182 (Notiz 59).

${ }^{37}$ Mann: Bilse und ich (wie Anm. 4). S. 105.

${ }^{38}$ In: Wysling (wie Anm. 11). S. 162 (Notiz 19). 
zwischen den beiden Typologien auf der Suche nach einer stabilen begrifflichen Definition. Dabei ist die Neigung zur Identifikation mit dem einen oder dem anderen Modell unübersehbar, was Mann zum regelrechten Herumirren im Dickicht der nicht miteinander in Einklang zu bringenden Aporien führt. Ausgangspunkt des groß angelegten Essays Der alte Fontane ist es, das Ethos als regulierende Kraft zu preisen, die es dem Künstler ermöglicht, über die Versuchung die Oberhand zu gewinnen, die handwerkliche Bewältigung des Stofflichen zugunsten der als verdächtig betrachteten Improvisation und Stimmung aufzugeben. Fontanes Absage an jede Art affektierten Geniekultes - so heißt es im 1910 in Maximilian Hardens Zukunft veröffentlichten Aufsatz rührt von dem Glauben her, dass künstlerisches Gelingen eher mit Erkenntnis als mit Rausch zu tun hat. Fontane schreibt Mann eine Form der Bescheidenheit zu, die "Ergebnis jener letzten Künstlerskepsis [ist], die sich gegen Kunst und Künstlerthum selber richtet und von der man sagen kann, daß alle Künstleranständigkeit in ihr beruht". ${ }^{39}$ Inspiration und Begeisterung werden durch Fleiß und handwerkliche Arbeit konterkariert; einzig und allein die "künstlerische Frömmigkeit", mit "Kunstfleiß" gepaart, verleiht dem Schaffenden "ein Recht auf Ironisirung des Geistes und der 'Literatur'". 40

Dabei zieht sich durch all diese Darlegungen eine identifikatorische Gestik, die u.a. um die nordische Herkunft Fontanes kreist, von der immer wieder die Rede ist. In Fontane sieht Mann eine bewundernswerte Vereinigung von "Bürgersinn für Zucht und Ordnung" und kühnem Radikalismus verwirklicht, die ihm zur klaren Einsicht in die "Fragwürdigkeit des Typus Künstler" ${ }^{41}$ verhilft. Die Beziehung, die hier zwischen Fontanes Ansichten und dem kulturkritischen Denken Nietzsches hergestellt wird, zielt offensichtlich darauf ab, einen Bund von Gleichgesinnten zu stiften, denen ein Eideshelferstatus zukommt, dem Mann sich nicht zuletzt im Hinblick auf deren gemeinsame Abneigung gegenüber der für die Musik Richard Wagners charakteristischen Mischung aus "Tempelkunst und heilige[m] Theater" 42 mit starker Kongenialität zuwendet. An Wagner macht sich allerdings ein weiteres Widerspruchselement bei der Suche nach festen Orientierungskriterien bemerkbar, die Mann um diese Zeit beschäftigt. Hätte Wagner in Geist und Kunst die Zielscheibe der angriffslustigen Aufzeichnungen Manns darstellen sollen, so gesteht dieser in der im Mai 1911 verfassten Auseinandersetzung mit Wagner, dass ausgerechnet das, was an Wagner verdächtig ist, das Wesentliche der modernen Kunst ausmacht.

\footnotetext{
${ }^{39}$ Thomas Mann: Der alte Fontane. In: Große Kommentierte Frankfurter Ausgabe (wie Anm. 4). Band 14/1. S. 254.

${ }^{40}$ Ebd. S. 256.

${ }^{41}$ Ebd. S. 255.

${ }^{42}$ Ebd. S. 265.
} 
In der Konstellation der Jahrhundertwende kann man nicht umhin, Wagner zu lieben, obwohl es sich dabei um "eine Liebe ohne den Glauben" 43 handelt.

Der durch Fontane vertretenen Künstlertypologie wohnt eine durchaus vergleichbare Ambivalenz inne. Der Romancier wird mit den Attributen versehen, die Mann in den Ende 1912 für die Zeitschrift März niedergeschriebenen Seiten zum Thema Der Künstler und der Literat dezidiert an der Seite des Literaten verorten wird. Die Schärfe der Beobachtungsfähigkeit, die dem Literaten eigen ist, erweitert sein Vermögen, Menschen und faktische Begebenheiten zu verstehen, in eine ausgesprochen moralische Richtung. Die Gabe, alles zu verstehen, veranlasst ihn, dem Gegenstand seines Verständnisses auch Vergebung entgegenzubringen, ${ }^{44}$ was Mann bei Fontane mit dessen in einem Brief enthaltener Aussage belegt, man müsse "den Künstlern gegenüber, wenn es wirkliche Künstler sind, Verzeihung üben". ${ }^{45}$ Dazu steht aber die Skepsis in sonderbarem Widerspruch, die Mann in den Notizen zu Geist und Kunst - diesmal eindeutig von der Warte des Dichters aus - ausgerechnet gegenüber einem solchen Erkenntnispotenzial des Literaten äußert:

Dieser [Der Litterat, F.T.] ist geneigt, Spekulation und Abgefeimtheit zu sehen, wo der Künstler in aller Unschuld und mit dem besten Gewissen seinem Geschmack Genüge that. Der Kritiker trägt die Last des Wissens für sich und andere, und von wie tiefer und leidvoller subjektiver Wahrheit auch seine Erkenntnisse über einen Künstler sein mögen, so sind sie doch, objektiv genommen, oft genug ganz und gar irrig, und der Künstler erzählt vielleicht mit heiterem Befremden von den schauerlichen und anstößigen Dingen, die man da über ihn zu Tage gebracht. [...] Die Kritiker nehmen die Künstler viel zu bewußt, viel zu moralisch. Sie glauben nicht genug an die Notwendigkeit und Verantwortungslosigkeit des künstlerischen Thuns. Sie nehmen an, daß es einem Künstler freigestanden hätte, ein Werk nicht oder anders zu schaffen, - ein immer wiederkehrendes Mißverständnis. ${ }^{46}$

Die Möglichkeit einer Annäherung der beiden Kategorien dank der vom Literaten großzügigerweise gespendeten Verzeihung, die sowohl in den Worten Fontanes als auch an einigen Stellen von Der Künstler und der Literat angedeutet wird, unterliegt in dieser Notiz des unausgeführten Aufsatzes einem radikalen Widerruf. Die zwei Typologien werden hier aufgrund ihrer nun als wesentlich unterschiedlich bezeichneten Naturen gegeneinander ausgespielt; ihre einzig denkbare gegenseitige Beziehung wird als Missverständnis abgetan. Die für das

\footnotetext{
${ }^{43}$ Thomas Mann: Auseinandersetzung mit Wagner. In: Große Kommentierte Frankfurter Ausgabe (wie Anm. 4). Band 14/1. S. 302.

44 "Seine Kenntnis des Herzens, sein Wissen um die Vieldeutigkeit und tiefe Unrichtbarkeit der menschlichen Handlungen läßt ihn verstehen, läßt ihn vergeben, führt ihn zur Güte". Thomas Mann: Der Literat. In: Große Kommentierte Frankfurter Ausgabe (wie Anm. 4). Band 14/1. S. 362.

${ }^{45}$ Mann: Der alte Fontane (wie Anm. 39). S. 255.

${ }^{46}$ In: Wysling (wie Anm. 11). S. 211 (Notiz 111).
} 
künstlerische Schaffen typischen Merkmale, die erwähnt werden, sind die aus der romantischen Tradition stammende "Notwendigkeit und Verantwortungslosigkeit", während das Erkenntnispotenzial des Literaten, das in Der alte Fontane noch gepriesen worden war, genauso wie seine Neigung zum Moralismus zur Last geworden ist. Aus dieser Perspektive sieht man ganz eindeutig, wie schwierig es ist, nicht nur die im Zeichen des mythisierten Begriffes 'drittes Reich' erträumte Synthese zwischen Plastischem und Kritischem zu verwirklichen, sondern auch jede mögliche Vereinigung zwischen den jeweiligen Eigenschaften des Literaten und des Künstlers zustande zu bringen - eine Vereinigung, die Mann allerdings im Prinzip nicht ausschließt, wie seine in dem an Samuel Lublinski adressierten Brief vom 13. Juni 1910 enthaltene Aussage ausführlich belegt:

Halten Sie die Vereinigung von Frivolität und Moralismus für möglich, daß Einer in der Kunst ein erquickliches Blendwerk sehe, hervorzubringen mit den feinsten sinnlichen und intellektuellen Zaubermitteln - und zugleich an künstlerischer Strenge und Gewissenhaftigkeit beinahe zu Grunde gehe? Ich fange an, sie für möglich zu halten, - etwa so, wie ich die Vereinigung von Skepsis und Leidenschaft für möglich halte. Ja, was ist die Kunst! Was ist der Künstler! ${ }^{47}$

Eine solche schwer zu gewinnende "Vereinigung von Frivolität und Moralismus" bzw. von "Skepsis und Leidenschaft" ist das heikle Thema, das den Kern der Betrachtungen eines Unpolitischen ausmacht und sich durch die Seiten dieses 'Künstlerwerkes' zieht. Man kann die Betrachtungen ohnehin als den Versuch lesen, eine passende Antwort auf die immer wieder gestellten Fragen zur Natur der Kunst und des Künstlers zu finden.

Vor dem Hintergrund des Ersten Weltkrieges nimmt Manns Arbeit an der typologischen Unterscheidung von Plastik und Kritik einen eher pragmatischen Charakter an. Dem war durch die Geschichte der Verwirrungen Aschenbachs im Tod in Venedig die Darstellung der Art und Weise vorausgegangen, wie leicht eine nicht durch einen langen selbsterzieherischen Reifungsprozess behutsam vorbereitete Synthese beider Gegenpole zum Scheitern verurteilt ist. Bei Aschenbach war der Drang nach Bereicherung der Form durch Leben wegen seiner Abstraktheit angeprangert worden. Dieser Drang scheint nun in den ersten Kriegsmonaten durch die neue 'Forderung des Tages' zu einer konkreten Verwirklichung gelangen zu können. ${ }^{48}$ In den kurz nach Kriegsausbruch

${ }^{47}$ Thomas Mann: Große Kommentierte Frankfurter Ausgabe (wie Anm. 4). Band 21: Briefe I. 1889 -1913. Hg. von Thomas Sprecher, Hans R. Vaget und Cornelia Bernini. Frankfurt/M.: Fischer 2002. S. 453f.

${ }^{48}$ Vgl. dazu Hermann Kurzke: Die Krise als Heimsuchung. Thomas Manns Deutungen des Ersten und des Zweiten Weltkrieges im Umfeld des "Zauberbergs" und des "Doktor Faustus". In: Schlechte Zeiten, gute Zeiten - Krisen als Herausforderungen. Hg. von Stefan Krimm und Martin Sachse. München: Bayerischer Schulbuch Verlag 2004. S. 138-157. 
verfassten, im November 1914 in der Neuen Rundschau veröffentlichten Gedanken im Kriege haben sämtliche zwischen Dichtung und Kritik vermittelnden Instanzen offensichtlich an Wert eingebüßt. Mann bemüht sich jetzt darum, künstlerisches Schaffen im Lichte seiner irrationalen, ja sakralen Fundierung neu zu legitimieren:

Kunst, wie alle Kultur, ist die Sublimierung des Dämonischen. Ihre Zucht ist strenger als Gesittung, ihr Wissen tiefer als Aufklärung, ihre Ungebundenheit und Unverantwortlichkeit freier als Skepsis, ihre Erkenntnis nicht Wissenschaft, sondern Sinnlichkeit und Mystik. ${ }^{49}$

Den Krieg nimmt Mann als einmalige Gelegenheit zur freien Entfaltung eines solchen Potenzials wahr. Den Fall zivilisationsgeregelter Zustände erlebt er als Chance zur Reautonomisierung der Kunst, die mit voller Entschiedenheit in die Sphäre der Romantik gerückt wird. Der Krieg erscheint ihm als "Heimsuchung" und "sittliche Not". ${ }^{50}$ Die innige Bindung von Kunst und Krieg, die in der Gestalt Aschenbachs heraufbeschworen worden war, erlangt eine historische, gemeinschaftsstiftende Dimension.

In einem solchen Zusammenhang erfahren die Züge des plastischen und des kritischen Künstlers eine drastische Verzerrung, die jede Vereinigung immer problematischer macht. Die Kluft, die sie trennt, vertieft sich so radikal, dass beide Typologien unkenntlich werden und viele ihrer jeweiligen Merkmale nun unter umgekehrtem Vorzeichen präsentiert werden. Aus dem fröhlichen, durch die Gaben seiner schöpferischen Natur erfüllten Dichter wird an mehreren Stellen der Betrachtungen eines Unpolitischen ein streng urteilender Asket, der von ästhetischer Lust fernbleibt und sein Wesen an eine düstere Moralvorstellung bindet, die Nähe zum Leben durch Vertrautheit mit dem Tode als Ausdruck einer höheren Verpflichtung 'ex negativo' schaffen will. Der Skepsis und Erkenntnis pflegende Literat wird dagegen immer öfter mit seinen latenten ästhetizistischen Neigungen konfrontiert, die ihm jede mögliche Standhaftigkeit verbieten und der Grund seiner Profilierungssucht im Umgang mit politischen Fragen sind. Was Mann in seiner Vorkriegsessayistik als eine typische Erscheinung der Dekadenz angesehen hatte, die Loslösung ästhetischen Schaffens von erkennenden und erklärenden Aufgaben, scheint er nun massiv zu betreiben.

Dabei geht es allerdings um schwankende, nie endgültig festgesetzte Charakterisierungen, deren eigentliches stabilisierendes Element mit der Schärfe und Zuspitzung ihrer Verbalisierung zusammenkommt. Dem durch die Romantik vermittelten Bild des Dichters als mit "dürerisch-faustischen Wesenszügen, [...]

\footnotetext{
${ }^{49}$ Thomas Mann: Gedanken im Kriege. In: Große Kommentierte Frankfurter Ausgabe (wie Anm. 4). Band 15/1. S. 28.

${ }^{50}$ Ebd. S. 33.
} 
metaphysische[r] Stimmung, [...] Ethos von 'Kreuz, Tod und Gruft', [...] Mischung aus Musik, Pessimismus und Humor" ${ }^{51}$ versehen, setzt Mann die in einer vergleichbaren romantischen Sphäre angesiedelte Figur des Ironikers entgegen, der nichts so sehr verabscheut wie verbindliche Werturteile, von dessen Warte aus die Welt als keinem höheren Einheitsprinzip zuzuordnende Mannigfaltigkeit erscheint. Parallel dazu verschiebt sich das Wesen des Literaten von dem unverantwortlichen, auf "Ruchlosigkeits- und Renaissance-Ästhetizismus" 52 hinauslaufenden Schönheitskult zu einem in seinem unmusischen Charakter unrettbaren Zustand der ständigen Politisierung, bei dem sich Geistigkeit in den hastigen Drang auflöst, zu den anstehenden Fragen schnell und in aller Öffentlichkeit Stellung zu nehmen. Die Tendenz, einmal geäußerte Standpunkte im Lichte weiterer, tiefer gehender Definitionsversuche zu revidieren, beruht zum Teil freilich auf der Entstehungsgeschichte der Betrachtungen, die in der Zeit vom Herbst 1915 bis Frühjahr 1918 alle Höhen und Tiefen des Kriegsgeschehens aus deutscher Sicht reflektieren. Die Veränderbarkeit des Ausgesagten stellt aber insofern vielmehr die ideologische und argumentative Grundbedingung dieses Großessays dar, als Mann ihm ausdrücklich die hybride Natur eines "Künstlerwerkes" 53 verleiht. Als polemischer Ausbruch über Begebenheiten zeitgeschichtlicher Art rücken die Betrachtungen einerseits in die Nähe des von Mann im Gegensatz zum 'Sein' immer wieder sehr entschieden abgelehnten 'Meinens', dessen aktivistische Prägung es von bleibender Sinnstiftung fernhält. Andererseits besteht das Spezifische an ästhetischen Argumentationsverfahren laut Mann gerade in ihrer Mehrdeutigkeit, die die geistige Erkenntnis von der Vielschichtigkeit des Lebens um jede konkrete Anwendbarkeit zur Aufhebung der bestehenden Verhältnisse bringt. Da "alles bloß Gesagte bedingt und angreifbar ist, so absolut und apodiktisch es auch im Augenblick empfunden werden und sich gebärden möge", ${ }^{54}$ soll das Vereinheitlichende an der geistigen Leistung, die Mann in den Betrachtungen hervorbringt, weniger in der sachlichen Nachprüfbarkeit der einzelnen Aussagen als vielmehr in der Kohärenz stilistischer und rhetorischer Art gesehen werden, die diesem Werk zugrunde liegt. Eine Kohärenz, die angesichts des wiederholten Perspektivenwechsels, dem sämtliche behandelten Gegenstände unterzogen werden, Manns ironische Grundüberzeugung durchscheinen lässt, in jeder Aussage komme auch ihr Gegenteil zum Ausdruck. Diesen Gedanken thematisiert er in dem u. a. der polemischen Auseinandersetzung mit Romain Rollands Pazifismus gewidmeten Kapitel Gegen Recht und Wahrheit:

Ich bin kein Systematiker, kein Doktrinär; ich fröne nicht dem schändlichen Irrwahn des Rechthabens, und nie werde ich mich mit einer Wahrheit, die ich für die

${ }^{51}$ Mann: Betrachtungen eines Unpolitischen (wie Anm. 1). S. 415.

${ }^{52}$ Ebd. S. 47.

${ }^{53}$ Ebd. S. 32.

${ }^{54}$ Ebd. S. 243. 
Wahrheit erachte, zur Ruhe setzen, und für den Rest meines Lebens davon zu zehren. Daran hindert mich Neigung zum Überdruß und zum Ekel und ein allzu lebhaftes Bedürfnis nach neuer, frischer und erfrischender Wahrheit. ${ }^{55}$

Manns in der Vorrede dargelegte Präsentation der Betrachtungen eines Unpolitischen als "Künstlerwerk" stützt sich nicht zuletzt auf das ihnen eigene konstruktivistische Profil, das durch mehrfachen Gebrauch von Zitaten entsteht. Lastet auf dem Inhaltlichen der vom Autor selbst diagnostizierte "Mangel an Stoffbeherrschung", ${ }^{56}$ so fasst Mann die mit dem Rekurs auf kongeniale Autoren verbundene Mehrstimmigkeit der Gedankenführung als das eigentlich Ästhetische an diesem Werk auf: "Das Zitieren wurde als eine Kunst empfunden, ähnlich derjenigen, den Dialog in die Erzählung zu spannen, und mit ähnlich rhythmischer Wirkung zu üben gesucht ...". 57

Die Darlegung ideologischer Positionen ist von ihrer ästhetisch-musikalischen Artikulation nicht zu trennen. Das den Betrachtungen zugrunde liegende "schwankende Gefühl", das Mann als die einzige Form bezeichnet, in der von einem "organischen und immer gegenwärtigen Grundgedanken" 58 in diesem Buch die Rede sein kann, macht sich immer wieder durch leitmotivisch entwickelte Variationen bemerkbar, die sich an manchen Stellen zu relativ stabilen thematischen Konstellationen kristallisieren, bei denen allerdings das einheitliche Modell eines auf Totalitätsvorstellungen hinausgehenden Kunstwerkes der parodistischen Infragestellung eines solchen Modells weichen soll. Mann hält sich an ein konstruktivistisches, auf souveräner Zitatenanwendung basiertes Verfahren, bei dem Verweise auf Referenztexte aus dem jeweiligen Kontext herausgerissen und oft unter umgekehrtem Vorzeichen umfunktionalisiert werden. ${ }^{59}$ Durch die polyphonische Akkumulation von fremden Stimmen entsteht eine diskursive Metaebene, an der die traditionelle Kunstwerkvorstellung als "ein Ganzes [...], das völlig sich rundet", 60 zugleich relativiert und bestätigt wird. Durch Kombinatorik führt Parodie

\footnotetext{
${ }^{55}$ Ebd. S. $189 f$.

${ }^{56}$ Ebd. S. 32

${ }^{57}$ Ebd. S. 33.

${ }^{58}$ Ebd. S. 32.

${ }^{59}$ Vgl. dazu Hermann Kurzke: Die Quellen der "Betrachtungen eines Unpolitischen". Ein Zwischenbericht. In: Internationales Thomas-Mann-Kolloquium 1986 in Lübeck. Hg. von Cornelia Bernini, Thomas Sprecher und Hans Wysling. Bern: Francke 1987. S. 291-310. Hermann Kurzke - Stephan Stachorski: Im Unterholz der Dichtung. Thomas Manns Essays und ihre Quellen. In: Thomas Mann Jahrbuch 12 (1999). S. 9-29.

${ }^{60}$ Gotthold Ephraim Lessing: Hamburgische Dramaturgie. In: Werke und Briefe in zwölf Bänden. Hg. von Wilfried Barner u. a. Frankfurt/M.: Deutscher Klassiker Verlag 1985-2003. Band 6. S. 577.
} 
verfremdende Elemente ein, die das Werk als absichtliche Inszenierung von in ihrer Geltung stark hinterfragten Totalitätsansprüchen zu entlarven schienen. Gerade im Gestus des argumentative Geflechte in musikalische Rhythmik umstrukturierenden Künstlers setzt sich aber eine verstärkte auktoriale Instanz durch, die die Intentionalität des im Geiste der Musik geführten assoziativen Verfahrens für sich beansprucht und darin eine spezifische Form literarischer Diskursivität anzeigt.

Der durch die Literatur im Dienst der Zivilisation verursachten Entmusikalisierung des deutschen Wesens entgegenzuwirken, stellt das Hauptanliegen Manns in den Betrachtungen eines Unpolitischen dar. Insofern plädiert er für Kultur als seelischen Urbesitz geschlossener Gemeinschaften, der auf gesamtmenschliche Einheit hinausläuft. Kultur erhält dadurch eine kosmopolitische Prägung, die mit spezifischen nationalen Eigenschaften so wenig in Widerspruch steht, dass Mann sie als für die deutsche Identität typischen Zug versteht. Die Unterscheidung zwischen 'Kultur' und 'Zivilisation', die Mann schon zur Zeit des 'Literatur-Essays' über Geist und Kunst beschäftigt hatte, wird in den Gedanken im Kriege endgültig systematisiert:

Zivilisation und Kultur sind nicht nur nicht ein und dasselbe, sondern sie sind Gegensätze, sie bilden eine der vielfältigen Erscheinungsformen des ewigen Weltgegensatzes und Widerspieles von Geist und Natur. Niemand wird leugnen, daß etwa Mexiko zur Zeit seiner Entdeckung Kultur besaß, aber niemand wird behaupten, daß es damals zivilisiert war. Kultur ist offenbar nicht das Gegenteil von Barbarei; sie ist vielmehr oft genug nur eine stilvolle Wildheit, und zivilisiert waren von allen Völkern des Altertums vielleicht nur die Chinesen. Kultur ist Geschlossenheit, Stil, Form, Haltung, Geschmack, ist irgendeine gewisse geistige Organisation der Welt, und sei das alles auch noch so abenteuerlich, skurril, wild, blutig, und furchtbar. Kultur kann Orakel, Magie, Päderastie, Vitzliputzli, Menschenopfer, orgiastische Kultformen, Inquisition, Autodafés, Veitstanz, Hexenprozesse, Blüte des Giftmordes und die buntesten Greuel umfassen. Zivilisation aber ist Vernunft, Aufklärung, Sänftigung, Sittigung, Skeptisierung, Auflösung, - Geist. ${ }^{61}$

In den Betrachtungen greift Mann im Wesentlichen auf diese Entgegensetzung zurück, wobei sich in seine Ansichten einige nicht unbedeutende terminologische Schwankungen einschleichen, wie dies bei dem 'Geist' der Fall ist, der bald als 'zivilisationskonform' ${ }^{62}$ dargestellt, bald im Zeichen der 'Kultur' gegen die 'Politik' ausgespielt wird:

Geist ist nicht Politik [...]. Der Unterschied von Geist und Politik enthält den von Kultur und Zivilisation, von Seele und Gesellschaft, von Freiheit und Stimmrecht, von Kunst und Literatur; und Deutschtum, das ist Kultur, Seele, Freiheit, Kunst und nicht Zivilisation, Gesellschaft, Stimmrecht, Literatur. ${ }^{63}$

${ }^{61}$ Mann: Gedanken im Kriege (wie Anm. 49). S. 27.

${ }^{62}$ Z. B. in Mann: Betrachtungen eines Unpolitischen (wie Anm. 1). S. 187.

${ }^{63}$ Ebd. S. 52. 
Fasst Mann deutsche Gesinnung als mit Kulturwerten aufs engste verflochten auf, so lässt er den Leser keinesfalls im Zweifel darüber, dass die geistige Lage im Krieg führenden Kaiserreich dem dominanten Einfluss der Zivilisation ausgesetzt ist. Bekanntlich wendet sich Mann in den Betrachtungen mit besonderer polemischer Wucht gegen symbolisch beladene Gegenspieler, denen ein Zustand der permanenten Politisierung zugesprochen wird. Dabei geht es in erster Linie um Frankreich als Hort der durch demokratische Zustände herbeigeführten politischen Egalisierung und um den Bruder Heinrich, der wegen seines Pazifismus und seiner Parteinahme für die Demokratisierung Deutschlands als Inbegriff des 'Zivilisationsliteraten' angeprangert und als solcher dem Typus 'Künstler' und 'Dichter' gegenübergestellt wird.

So unleugbar die hohe Brisanz einer solchen familiären Auseinandersetzung auch ist, gilt Heinrich in den Betrachtungen weit über seine persönlichen Ansichten hinaus als dialektischer Gegenpol, den Mann zur Fortsetzung jener analytischen Arbeit einsetzt, die von seinen ersten Essays an zur Präzisierung einiger für seine Kunstanschauung grundlegender Kategorien dient. In seinem affirmativen Gestus verfolgt der Zivilisationskritiker in der Tat eher auf sich selbst bezogene Absichten:

Dieses Buch ist Selbsterklärung und Selbstaufklärung, - keine Polemik; obgleich die Erklärung meinerselbst notwendig zuweilen polemische Formen annimmt. Es möchte Gestalt sein, - und was Polemik scheinen mag, ist eben nur Wegmeißelung, Ausbildung, Kontur. So will ich auch hier nur mich erklären und umreißen, nicht polemisieren. ${ }^{64}$

Zur eigenen Standortbestimmung gehört auch und überhaupt die schonungslose Einsicht in die Tatsache, dass der in den Betrachtungen unternommene Kampf ein Rückzugsgefecht ist. Die konservative Grundeinstellung seines Buches legt Mann als notwendigen Ausgleich zu einer Fortschrittstendenz aus, die ihm sowieso als geschichtsimmanent erscheint. ${ }^{65}$ Ausklang und 'der Weisheit letzten Schluss' der gesamten Abhandlung bildet eben eine solche Erkenntnis, die Mann durch einige Worte Friedrich von Gentz' zum Ausdruck bringt:

Die Weltgeschichte ist ein ewiger Übergang vom Alten zum Neuen. Im steten Kreislauf der Dinge zerstört alles sich selbst, und die Frucht, die zur Reife gediehen ist,

${ }^{64}$ Ebd. S. 155.

${ }^{65}$ Dazu lese man Terence James Reed: “... Daß alles verstehen alles verzeihen heiße ..." Zur Dialektik zwischen Literatur und Gesellschaft bei Thomas Mann. In: Internationales Thomas-Mann-Kolloquium (wie Anm. 59). S. 159-173 und Peter Pütz: Thomas Manns Wandlung vom 'Unpolitischen' zum 'Demokraten'. In: Literatur der Weimarer Republik. Kontinuität - Brüche. Hg. von Michael Klein, Sieglinde Klettenhammer und Elfriede Pöder. Innsbruck: Institut für Germanistik 2002. S. 45-58 (im Besonderen S. 51). 
löset sich von der Pflanze ab, die sie hervorgebracht hat. Soll aber dieser Kreislauf nicht zum schnellen Untergang alles Bestehenden, mithin auch alles Rechten und Guten führen, so muß es notwendig neben der großen, zuletzt immer überwiegenden Anzahl derer, welche für das Neue arbeiten, auch eine kleinere geben, die mit Maß und Ziel das Alte zu behaupten und den Strom der Zeit, wenn sie ihn auch nicht aufhalten kann noch will, in einem geregelten Bette zu erhalten sucht. ${ }^{66}$

Das Beharren auf dem Bestehenden im Strudel der Erneuerungskräfte, die auf das Kommende weisen, bezeichnet Mann als typisches Beispiel von "konservativer Ironie" ${ }^{67}$ Angesichts der Vermittlungsfunktion zwischen den Extremen, die bei Mann der Kunst zukommt, erhält die Ironie als verbindende Instanz unter divergierenden Prinzipien eine Schlüsselstellung in seiner gesamten Weltanschauung. Der relativierende Gestus des Ironikers, der die bestehenden Verhältnisse sehr wohl einer eingehenden Kritik unterzieht, wird durch die Bejahung gemildert, zu der sich Mann dem Seienden gegenüber verpflichtet glaubt. Insofern speist sich Ironie aus jener erotischen Anziehung, die dazu führt, das Existierende aufgrund seiner bewährten Beständigkeit in seiner Geltung anzuerkennen. Die damit einhergehende Verabsolutierung des Lebendigen konterkariert Mann aus kulturkritischer Perspektive, indem er Konservatismus als Schutz bestimmter Wertvorstellungen humanitärer Prägung heraufbeschwört, die aus seiner Sicht in der bürgerlich-romantischen Weltordnung verwurzelt sind.

Zum Wesen der Ironie gehört allerdings auch eine Form der Bescheidenheit, die mit der klaren Erkenntnis zusammenhängt, dass die Kritik an der Gegenwart nicht in der Lage ist, für irgendeine Verbesserung der objektiven Zustände zu sorgen. Das einer solchen Kritik eigene Potenzial besteht vielmehr darin, spielerische, ja unpolitische Alternativen $\mathrm{zu}$ ebendiesen Zuständen zu entwerfen, deren höchsten Ausdruck Mann im Verfahren der künstlerischen Gestaltung verwirklicht sieht. Insofern, als Ironie dazu noch "rückwärts gewandte Skepsis" 68 ist, arbeitet der ironische Künstler vorzugsweise mit vorgegebenen, mit der Tradition eng verbundenen Materialien, die trotz ihres manifesten unzeitgemäßen Charakters einen unangefochtenen ästhetischen sowie ethischen Wert bewahren. Dabei schwebt Mann gerade ein

${ }^{66}$ Mann: Betrachtungen eines Unpolitischen (wie Anm. 1). S. 585.

${ }^{67} \mathrm{Ebd}$. Zu den Begriffen 'Konservatismus' und 'konservative Ironie' bei Mann vgl. Kurzke: Thomas Mann (wie Anm. 13). S. 165-170. Menno van Heeckeren: Thomas Mann: Parteigänger oder Untergangsprophet der 'deutschen Ideologie'? Über das Verhältnis von Literatur und Zeitgeschichte im Frühwerk Thomas Manns. In: Neophilologus 85 (2001). S. 245-256. Baal Müller: Konservatismus als erotische Ironie Zur Poetik der Differenz in Thomas Manns "Betrachtungen eines Unpolitischen". In: Paradoxien der Wiederholung. Hg. von Robert André und Christoph Deupmann. Heidelberg: Winter 2003. S. 119-136.

${ }^{68}$ Mann: Betrachtungen eines Unpolitischen (wie Anm. 1). S. 579. 